\title{
Resuscitating the elderly: what do the patients want?
}

Peter Bruce-Jones, Helen Roberts, Lesley Bowker and Veneta Cooney Department of Medicine for the Elderly, Poole Hospital and Elderly Care Unit, Southampton General Hospital

\begin{abstract}
Objectives-To study the resuscitation preferences, choice of decision-maker, views on the seeking of patients' wishes and determinants of these of elderly hospital in-patients.

Design-Questionnaire administered on admission and prior to discharge.

Setting-Two acute geriatric medicine units

(Southampton and Poole).

Participants-Two hundred and fourteen consecutive

consenting mentally competent patients admitted to

hospital as emergencies.

Results-Resuscitation was wanted by $60 \%$, particularly married and functionally independent patients and those who had not already considered it.

Not wanting resuscitation was associated with lack of social contacts. Sixty-seven per cent welcomed enquiry about their preferences and $78 \%$ wanted participation in decisions, $43 \%$ as sole decision-maker. Wishing to choose oneself was associated with not wanting resuscitation, prior knowledge of it, and lack of a spouse. Patients' opinions remained stable during their admission.

Conclusions-Discussion of resuscitation is practical on hospital admission without causing distress and the views expressed endure through the period of hospitalisation. Elderly patients' attitudes depend partly on personal health and social circumstances. This may assist doctors when patients are unable to participate themselves.
\end{abstract}

\section{Introduction}

Although originally intended for use following acute insults ${ }^{1}$ cardiopulmonary resuscitation (CPR) is now used widely in hospitals despite its usual lack of success, particularly in established illness. ${ }^{2}$ Unlike the large majority of treatments it must be selected before any need arises. This involves assessments of "quality of life" as well as medical prognosis. Although it is unclear whether advanced age

\section{Key words}

Resuscitation decisions; advance directives; patients' opinions. independently predicts non-survival after CPR, ${ }^{2} \stackrel{\text { N }}{N}$ increasing morbidity and loss of independence in oldew age may influence patients' attitudes towards life- $\vec{c}$ sustainment. These attitudes are predicted poorly by doctors $^{45}$ and "quality of life" judgments require direct patient input. ${ }^{67}$ Thus there have been many $\vec{c}$ recommendations that patients' own views be $=$ incorporated in CPR decisions. ${ }^{6-13}$ Despite proposed guidelines, ${ }^{91014}$ British practice remains $\vec{\bullet}$ informal and inconsistent, and patients are consulted infrequently. ${ }^{15}$

Most previous British studies of patients' opinions have questioned them at discharge from hospital, yet it is on admission that resuscitation plans are firsto made. We have studied the resuscitation wishes and흐 determinants of these in patients on admission to the Elderly Care Units of Southampton Generalo Hospital and Poole Hospital.

\section{Patients and methods}

Consecutive patients admitted as emergencies were interviewed within two working days of admission, $\underline{3}$. using a questionnaire (see appendix). Exclusionso included moribund condition, coma, a Hodkinson Abbreviated Mental Test ${ }^{16}$ (a standard instrument ino geriatric medical practice) score less than $7 / 10$, overt? mental illness (taking antidepressant or major tran-0 quilliser drugs or under psychiatric care), dysphasia and other significant communication difficulties. Theo commonest exclusion was impaired mental function $N$ (186 patients). Fifty-six eligible patients $(21 \%) \mathrm{W}^{\mathrm{N}}$ declined to participate. Two hundred and fourteeno patients with a wide range of acute medical conditions were interviewed (Southampton 102, Poole 112), out of 595 acute admissions to the units during the study? period $(36 \%)$. They were aged 66-97 (median 84), and $65 \%$ were women. Subjects were given a briefo description of CPR (appendix) stating that resuscitation is "often unsuccessful" but not giving outcome statistics.

The three core questions asked were:

(a) If your heart were suddenly to stop beating in hospital would you want vigorous attempts to beo made to revive you? 
(b) Would you want this to be decided by your self/family/doctor or a joint decision?

(c) Do you think you should be asked your wishes regarding resuscitation when you come into hospital?

Other questions focused on what factors were thought most important, and previous consideration and discussion of CPR. Knowledge and experience of CPR, perceived health and dependency, the Barthel Activities of Daily Living Index and social history were recorded. (The Barthel Index ${ }^{17}$ is a simple objective measure of functional ability and dependency and is the most widely used such instrument by geriatric medicine physicians, approved by the Royal College of Physicians and the British Geriatrics Society.) Finally, patients were asked whether they had found the questionnaire stressful. The core questions were repeated within two days of discharge in 121 patients ( $56 \%$ ); the remainder were discharged very soon after the initial interview, died in hospital or were lost to follow-up. The study received local ethical committee approval and each subject gave written consent.

The centres were treated as a single population. Associations between answers to the three core questions and demographic and background health and social factors were tested by Chi-square tests for categorical variables and the Mann-Whitney test, or the Kruskal-Wallis test, as appropriate for continuous variables.

\section{Results}

The questionnaire was well received; only eight respondents $(4 \%)$ replied that it was stressful. Nearly all $(95 \%)$ the subjects had been in hospital previously. Ten patients said they had received CPR; five remembered what happened. Some knowledge of CPR was claimed by 116 patients $(54 \%)$, mostly gained from television. Seventeen patients $(8 \%)$ had participated in a resuscitation decision about a relative. Overall, usual health $(38 \%$ of respondents), age (36\%), "life at home" $(32 \%)$

Table 1 Answers to the three core questions: numbers (\%)*

\begin{tabular}{lcc} 
& On admission & At discharge \\
\hline (a) Resuscitation preference & $\mathrm{n}=214$ & $\mathrm{n}=118$ \\
CPR & $129(60)$ & $63(53)$ \\
No CPR & $64(30)$ & $47(40)$ \\
Not sure & $21(10)$ & $8(7)$ \\
(b) Who should decide?* & $\mathrm{n}=211$ & $\mathrm{n}=119$ \\
Patient themself & $91(43)$ & $56(47)$ \\
Family & $17(8)$ & $8(7)$ \\
Doctor & $30(14)$ & $15(13)$ \\
Joint decision & $73(34)$ & $40(34)$ \\
(c) Should patients be asked? & $\mathrm{n}=214$ & $\mathrm{n}=115$ \\
Yes & $144(67)$ & $82(71)$ \\
No & $57(27)$ & $33(29)$ \\
Not sure & $13(6)$ & 0 \\
\hline
\end{tabular}

^Percentages rounded to whole integers. and the family's wishes $(28 \%)$ were the considerations thought most important. Answers to the core questions are given in Table 1.

\section{RESUSCITATION PREFERENCE}

Most patients wanted CPR both on admission $(60 \%)$ and at discharge (53\%). At discharge twenty patients had changed their minds but there was no statistically significant trend.

Table 2 displays the characteristics of patients wanting and not wanting CPR. More of the married patients $(73 \%)$ wanted CPR than other groups, especially the widowed $(52 \% ; \mathrm{p}<0.01)$. The patients wanting CPR were younger than those saying "no" but only women showed this difference when each sex was analysed separately. No significant age difference was found within each marital status grouping. Similarly, a greater proportion of men $(77 \%)$ than women $(51 \%)$ wanted CPR, but not when corrected for marital status. Sixty-six patients $(31 \%)$ had already considered their resuscitation wishes and $37(17 \%)$ had discussed them with someone, in most cases (31) with a family member. Fewer of these patients $(42 \%)$ wanted CPR than those who had not already considered their wishes $(68 \%)$. Patients not wanting CPR tended to be widowed $(72 \%)$, had fewer social contacts and higher self-rated dependency, and two-thirds needed help with daily activities. Most $(76 \%)$ wished to decide for themselves (Table 3 ) and quoted age as a deciding factor $(66 \%, \mathrm{p}<0.001)$. In contrast, deciding factors for those wanting CPR were their usual health (48\%), "life at home" $(41 \%)$, and their family's wishes $(38 \%)$.

\section{WHO SHOULD DECIDE?}

Three-quarters of patients wanted participation, alone or jointly. Results at discharge were very similar and the thirty-seven patients who changed their choice displayed no statistically significant trends. Single and widowed patients (and therefore women) favoured deciding for themselves, whilst a

Table 2 Characteristics of patients wanting and not wanting CPR

\begin{tabular}{|c|c|c|c|c|}
\hline & $C P R$ & No $C P R$ & & \\
\hline Total & 129 & 64 & & \\
\hline Median age & $83 \cdot 0$ & $85 \cdot 5$ & $\star$ & (b) \\
\hline women & 71 & 52 & & \\
\hline men & 58 & 12 & $\star \star \star$ & (a) \\
\hline Marital status: single & 11 & 6 & & \\
\hline married & 51 & 11 & $\star \star$ & (a) \\
\hline widowed & 64 & 46 & & \\
\hline Median pre-admission Barthel score & 18 & 17 & $\star$ & (b) \\
\hline Self-rated dependency (scale $0-10$ ) & 2 & 5 & $\star \star$ & (b) \\
\hline Independent for $\mathrm{ADL}$ & $7 \overline{3}$ & 22 & $\star \star \star$ & (a) \\
\hline Needing help with ADL & 56 & 42 & & \\
\hline \multicolumn{5}{|l|}{ Previously considered CPR wishes: } \\
\hline Yes & 28 & 31 & & \\
\hline No & 100 & 32 & $\star \star \star$ & (a) \\
\hline
\end{tabular}

${ }^{\star} \mathrm{p}<0.05 ;{ }^{\star \star} \mathrm{p}<0.01 ;{ }^{\star \star \star} \mathrm{p}<0.001$

(a) $\chi^{2}$ test; (b) Mann-Whitney test. 
Table 3 Who should decide? Characteristics of subjects favouring each type of decision

\begin{tabular}{|c|c|c|c|c|c|c|c|}
\hline & & Self & Family & Doctor & foint & & $\because$ \\
\hline & & 91 & 17 & 30 & 73 & & \\
\hline Median age & & $85 \cdot 0$ & $79 \cdot 0$ & $81 \cdot 5$ & $84 \cdot 0$ & $\star \star \star$ & (b)o \\
\hline Sex: & women & 67 & 12 & 14 & 44 & $\star$ & (a) $\underline{\bar{\sigma}}$ \\
\hline Married patients & men & 24 & 5 & 16 & $\begin{array}{l}29 \\
30\end{array}$ & & $\overline{\bar{\omega}}$ \\
\hline Single/widowed & & 70 & 11 & $\begin{array}{l}13 \\
17\end{array}$ & $\begin{array}{l}30 \\
38\end{array}$ & $\star \star$ & (a) $\overrightarrow{\widetilde{D}}$ \\
\hline Prior knowledge of CPR: & yes & 55 & 4 & 10 & 45 & $\star \star$ & (a) \\
\hline & no & 35 & 13 & 20 & 28 & & \\
\hline CPR wish: & yes & 36 & 16 & 27 & 49 & $\star \star \star$ & (a) \\
\hline & no & 48 & 0 & 1 & 14 & & (a) \\
\hline \multicolumn{8}{|l|}{ Deciding factors: } \\
\hline current illness & & 12 & 1 & 8 & 13 & & \\
\hline usual health & & 31 & 4 & 17 & 27 & & \\
\hline life at home & & 27 & 4 & 10 & 26 & & \\
\hline wishes of family & & 11 & 11 & 10 & 26 & $\star \star \star$ & (a) $\overline{3}$ \\
\hline age & & 40 & 3 & 9 & 23 & & $\vec{D}$ \\
\hline Agree with being asked wishes on admission & yes & 66 & 9 & 12 & 56 & $\star \star \star$ & (a) \\
\hline & no & 20 & 6 & 18 & 13 & & \\
\hline
\end{tabular}

greater proportion of married patients than of other groups wanted a joint decision (Table 3). Patients desiring participation, alone or jointly, were older than those wanting their family or doctor to decide, but when analysed by sex and by marital status, only women and single patients showed this difference, suggesting that it was due to marital status. Patients with prior knowledge of CPR were less likely than those without to leave the decision to others. Those who wished to choose for themselves tended to have previously considered (38/91 patients, 42\%; $\mathrm{p}<0.05)$ and to have rejected CPR (48/84 patients, $57 \% ; \mathrm{p}<0.001)$ and attached less importance to their family's wishes. Only eight per cent of patients wanted their family alone to make the decision.

\section{SHOULD PATIENTS BE ASKED?}

Two thirds of patients said yes. There were no statistically significant trends between admission and discharge. As expected, those who wanted to choose themselves about CPR, alone or jointly, tended to agree with being asked.

\section{Discussion}

One concern with questionnaires such as this is whether respondents give their true opinions or perceived "proper" answers. It is impossible to be absolutely certain of this. However, when consenting to the study patients were asked to answer honestly and their opinions were sought using a uniform questionnaire and as standard an interview as possible. By so doing, by giving a brief description of CPR and by assessing prior knowledge we also attempted to control for known sources of variability of response.

We have found that elderly patients welcome discussion of resuscitation soon after emergency admission when such discussions are most relevant, confirming the results of previous studies at other stages..$^{18-22}$ Our results, like those of Morgan et al ${ }^{21}$ and Mead and Turnbull ${ }^{22}$ do not supportphysicians' common fear of provoking anxiety. ${ }^{23}{ }^{24} \subseteq$ There is some evidence that these discussions may improve psychological wellbeing. ${ }^{25}$

Most subjects wished to decide about resuscitation themselves, either alone or jointly, particularly those with prior knowledge of CPR or without a spouse. When patients are very ill, doctors commonly rely heavily on the views of relatives regarding the aggres-o siveness of treatment and life-sustaining procedures. $\frac{\mathrm{Q}}{8}$ Our results indicate that few patients favour this approach and this has practical implications foro를 managing a very ill patient. In previous British studies more patients (43-69\%) have wanted CPR decisions to be taken by their doctors. ${ }^{182122} 26$. Responses may depend on the precise questions $\overline{3}$ asked, and socioeconomic differences between the study populations may also be important. Studies 3 from the USA agree with our finding that mosto elderly people want some say in the matter..$^{20} 27$

One objection to discussing CPR on admission is that patients' judgment may be impaired by acute illness. Importantly very few of our sample hado changed their minds by discharge. In a recent study. most patients initially against CPR scored highly ono a depression inventory and some had changed theiru minds by discharge, but the numbers involved weren very small. ${ }^{28}$ We excluded patients with known ${ }_{\sigma}^{\omega}$ depression. Directives made earlier may avoid this problem but the durability of patients' opinions overc longer periods cannot be assumed. ${ }^{25}$

Participation in decisions requires an understand $-?$ ing of the procedure in question, and this is generallyo lacking. As in other British studies, ${ }^{18}{ }^{26}$ only half ouro patients had even partial knowledge of CPR. Eveno patients relatively knowledgeable about CPR have been found grossly to overestimate the chance of success. $^{22} 2527$ This may explain our finding, ino common with several studies, that elderly patients usually do want CPR even if they are severely ill on. disabled. ${ }^{45222629}$ Those of our subjects who had 
already considered resuscitation were more equivo$\mathrm{cal}$, in keeping with the small numbers (5-7\%) wanting CPR in studies where more detailed outcome information has been provided. ${ }^{31} 31$

Some studies have failed to find psychosocial predictors of patients' choices ${ }^{1922} 26$ whilst others suggest that old age lessens the desire for resuscitation $^{29} 32$ or that men desire it more than women. ${ }^{1829}$ In our study these differences were due to marital status, and we have confirmed that social isolation and dependency are determinants of patients' opinions.

Although some trends can be seen, the attitudes of individuals remain largely unpredictable. This does not mean that patients' wishes should universally be solicited: when outcome predictors show that CPR would be medically futile no true choice exists. ${ }^{6}$ In these situations patient autonomy and patients' desire for participation are more appropriately satisfied by discussions aimed at "an understanding and acceptance of the clinical decision" which is taken by professionals. ${ }^{7}$ Greater restriction of CPR according to prognostic criteria will also reduce the number of "grey cases" in which the main issue is quality of life and patients' opinions are most important. Whilst most guidelines do not recommend soliciting these opinions, patients expect their doctors to initiate the discussion ${ }^{19}{ }^{23}$ and have been shown to be able to assimilate and use appropriate information rationally. We conclude that patient participation in resuscitation decisions is practical, reliable and unstressful as well as being desirable and popular. Elderly patients' views appear to be stable for the period of hospitalisation, and thus questioning soon after admission is worthwhile.

Dr Peter Bruce-fones, $M B, C h B, M R C P(U K)$, is Senior Registrar, Department of Medicine for the Elderly, Royal Bournemouth Hospital. Dr Helen Roberts, BCs, MB, ChB, MRCP(UK), is Consultant Physician, Elderly Care Unit, Southampton General Hospital. Dr Lesley Bowker, BM, MRCP(UK), is Medical Registrar, Royal Hampshire County Hospital, Winchester. Dr Veneta Cooney, MBBS, is Senior House Officer, Poole and Royal Bournemouth Hospitals.

\section{References}

1 Kouwenhoven WB, Jude JR, Knickenbocker GG, Baltimore MSE. Closed-chest cardiac massage. fournal of the American Medical Association 1960; 173: 94-7.

2 Dautzenberg PLJ, Broekman TCJ, Hooyer C, Schonwetter RS, Duursma SA. Review: Patient-related predictors of cardiopulmonary resuscitation of hospitalised patients. Age and Ageing 1993; 22: 464-75.

3 O'Keefe S, Redahan C, Keane P, Daly K. Age and other determinants of survival after in-hospital cardiopulmonary resuscitation. Quarterly fournal of Medicine 1991; 81: 1005-10.

4 Seckler AB, Meier DE, Mulvihill M, Cammer Paris BE. Substituted judgment: how accurate are proxy predictions? Annals of Internal Medicine 1991; 115: 92-8.
5 Uhlmann RF, Pearlman RA, Cain KC. Physicians' and spouses' predictions of elderly patients' resuscitation preferences. Fournal of Gerontology 1988; 43: M115-21.

6 Florin D. "Do not resuscitate" orders: the need for a policy. Fournal of the Royal College of Physicians of London 1993; 27: 135-8.

7 British Medical Association and Royal College of Nursing. Decisions relating to cardiopulmonary resuscitation. Joint statement in association with the Resuscitation Council (UK). London: 1993.

8 Blackhall LJ. Must we always use CPR? New England fournal of Medicine 1987; 317: 1282-5.

9 British Geriatrics Society. Advice on resuscitation policies. London: 1993.

10 Doyal L, Wilsher D. Withholding cardiopulmonary resuscitation: proposals for formal guidelines. British Medical fournal 1993; 306: 1593-6.

11 House of Lords. Report of the Select Committee on Medical Ethics. London: HMSO, 1994.

12 Podrid PJ. Resuscitating the elderly: a blessing or a curse? Annals of Internal Medicine 1989; 111: 193-5.

13 Wanzer SH, Federman DD, Adelstein SJ, Cassel CK, Cassem EH, Cranford RE, et al. The physician's responsibility toward hopelessly ill patients. New England fournal of Medicine 1989; 320: 844-9.

14 Williams $R$. The "do not resuscitate" decision: guidelines for policy in the adult. Fournal of the Royal College of Physicians of London 1993; 27: 139-140.

15 Keatinge RM. Exclusion from resuscitation. Fournal of the Royal Society of Medicine 1989; 82: 402-5.

16 Hodkinson HM. Evaluation of a mental test score for assessment of mental impairment in the elderly. Age and Ageing 1972; 1: 233-8.

17 Mahoney FI, Barthel DW. Functional evaluation: the Barthel Index. Maryland Medical fournal 1965; 14: 61-5.

18 Gunasekera NPR, Tiller DJ, Clements LTS-J, Bhattacharya BK. Elderly patients' views on cardiopulmonary resuscitation. Age and Ageing 1986; 15: 364-8.

19 Lo B, McLeod GA, Saika G. Patient attitudes to discussing life-sustaining treatment. Archives of Internal Medicine 1986; 146: 1613-5.

20 Stolman CJ, Gregory JJ, Dunn D, Levine JL. Evaluation of patient, physician, nurse and family attitudes toward do not resuscitate orders. Archives of Internal Medicine 1990; 150: 653-8.

21 Morgan R, King D, Prajapati C, Rowe J. Views of elderly patients and their relatives on cardiopulmonary resuscitation. British Medical fournal 1994; 308: 1677-8.

22 Mead GE, Turnbull CJ. Cardiopulmonary resuscitation in the elderly: patients' and relatives' views. Fournal of Medical Ethics 1995; 21: 39-44.

23 Kohn M, Menon G. Life prolongation: views of elderly outpatients and health care professionals. Fournal of the American Geriatrics Society 1988; 36: 840-4.

24 Schade SG, Muslin H. Do not resuscitate decisions: discussions with patients. Fournal of Medical Ethics 1989; 15: 186-90.

25 Kellogg FR, Crain M, Corwin J, Brickner PW. Lifesustaining interventions in frail elderly persons. Talking about choices. Archives of Internal Medicine 1992; 152: 2317-20.

26 Liddle J, Gilleard C, Neil A. The views of elderly patients and their relatives on cardiopulmonary resuscitation. Fournal of the Royal College of Physicians of London 1994; 28: 228-9. 
27 Miller DL, Jahnigen DW, Gorbien MJ, Simbartl L. Cardiopulmonary resuscitation: how useful? Attitudes and knowledge of an elderly population. Archives of Internal Medicine 1992; 152: 578-82.

28 Potter JM, Stewart D, Duncan G. Living wills: would sick people change their minds? Postgraduate Medical fournal 1994; 70: 818-20.

29 Frankl D, Oye RK, Bellamy PE. Attitudes of hospitalized patients toward life support: a survey of 200 inpatients. American fournal of Medicine 1989; 86: 645-8.

30 Murphy DJ, Burrows D, Santilli S, Kemp AW, Tenner $S$, Kreling B, Teno J. The influence of the probability of survival on patients' preferences regarding cardiopulmonary resuscitation. New England Fournal of Medicine 1994; 330: 545-9.

31 Wagner A. Cardiopulmonary resuscitation in the aged. A prospective survey. New England fournal of Medicine 1984; 310: 1129-30.

32 Füsgen I, Summa J-D. How much sense is there in an attempt to resuscitate an aged person? Gerontology 1978; 24: 37-45.

\section{Appendix: Information for participants}

There is a lot of debate at the moment about what should happen if a patient has a "cardiac arrest", and I would like to ask you for your opinions.

A cardiac arrest is where a patient's heart suddenly and unexpectedly stops beating (ie, it does not mean the gradual slowing and weakening of the heart beat in someone who is known to be dying). Nowadays it is sometimes possible to revive someone in this situation using cardiac massage (compressing the chest), drugs and electric shocks. Such resuscitation attempts are often unsuccessful, and they may revive only the heart and breathing but not the whole person. Therefore, this treatment is not given to all hospital patients. It may be withheld because of a very poor chance of success, or because it is considered kinder not to revive someone who has a serious incurable disease. Usually in this country it is the doctors who make this judgment, and very little is known about patients' own views.

We would therefore like to ask you some questions about your opinion on resuscitation and what things have influenced it. Your answers will be treated as strictly confidential. You may withdraw from the study at any stage if you wish and this will not affect your care in any way.

\section{CPR patient questionnaire \\ Part 1: within two working days of admission}

Subject number

Age:

Sex:

Marital Status:

Cultural origin:

Mental test score on admission:

$/ 10$

Barthel score on admission:
1. How satisfied are you with your recent quality of life? (tick)

$\begin{array}{ll}\text { Totally } & \text { unsatisfied } \\ \text { Moderately } & \text { unsatisfied } \\ \text { Partly } & \text { unsatisfied } \\ \text { Partly } & \text { satisfied } \\ \text { Moderately } & \text { satisfied } \\ \text { Totally } & \text { satisfied }\end{array}$

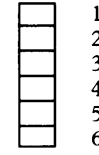

2. How do you rate your health (for your age)? (underline) above average average below average

Social history

3. Are you living with?

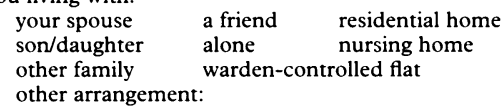

4. If you live alone, how much contact do you have with your family?:

less than once a week more than once a week none

5. How much social contact do you have outside home?: frequent infrequent none

6. Do you look after a disabled person yourself Yes/No

7. Do you need any help with basic everyday activities? no occasionally usually

8. On a scale of $0-10$, how dependant on other people are you? $(0=$ fully independent; $10=$ dependant for everything)

Medical history

^9. Current medical problem:

$\star 10$. Principal background illnesses and disabilities:

11. How many times have you been in hospital before? none $\quad 1-5 \quad 6-10 \quad>10$

Previous experience

12. Have you ever been resuscitated?

13. Do you remember what happened? Yes / No / don't know

14. Do you know what is actually done when someone is resuscitated? Yes / No

How did you learn about resuscitation? - through relatives/friends

- through the media - first hand

Yes / No

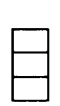

Opinions about resuscitation

16A. If your heart were suddenly to stop beating in hospital would you want vigorous attempts to be made to revive you?

Yes No Not sure

17. Have you thought about this before? Yes/No

$18 \mathrm{~A}$. Would you want this to be decided by your: self alone family alone doctor alone self and family/doctor jointly?

19A. Which of the following factors do you consider the most important for your choice?: (tick)
a) this illness?
b) your usual state of health?
c) life at home?
d) the wishes of your family?
e) religious beliefs?
f) your age?
g) your previous experience of resuscitation?
h) other reasons:

20. Have you discussed this question with:

$$
\begin{aligned}
& \text { - your family? } \\
& \text {-- your family doctor? } \\
& \text { - anyone else? } \\
& \text { If so, whom? }
\end{aligned}
$$

21. Have you ever been involved in a similar decision about a close relative

Yes / No

22A. Do you think you should be asked your wishes regarding resuscitation when you come into hospital?

23A. Have you found this questionnaire stressful

Please answer the following questions by ticking the box or underlining your chosen answer as appropriate. Please ignore questions 9 and 10 (marked “»”); these will be completed by the investigators. 


\section{Part 2: within two days of discharge}

Please answer the following questions by underlining/ticking the answers as appropriate.

Subject number:

16B. If your heart were suddenly to stop beating in hospital would you want vigorous attempts to be made to revive you?

$$
\text { Yes No sure }
$$

18B. Would you want this to be decided by your:

self alone family alone doctor alone

self and family/doctor jointly?

19B. Which of the following factors do you consider the most important for your choice?:
a) this illness
b) your usual state of health?
c) life at home?
d) the wishes of your family?
e) religious beliefs?
f) your age?
g) your previous experience of resuscitation?
h) other reasons:

\section{News and notes}

\section{Fourth International Symposium on Sexual Mutilations}

The Fourth International Symposium on Sexual Mutilations will be held at the University of Lausanne in Switzerland from the 9th to the 11 th of August this year.

The symposium is for medical professionals and others interested in the human rights, medical, and ethical implications of male and female sexual mutilations. Presenters will include health care professionals, scholars and legal experts from Europe, North America, Australia and Africa.

For further information contact: George C Denniston, MD, MPH, President, DOC, Doctors Opposing Circumcision, 2442 NW Market St Suite 42, Seattle, WA 98107, USA. Telephone: 415-488-9883. DOC4thISSM@aol.com. 